\title{
Preparation of silica antireflection film based on sol-gel method
}

\author{
Zheyu Jiang ${ }^{1}$, Qiuyi Wan ${ }^{1}$, Jiarong Liu ${ }^{2}$ and Xiujun Tian ${ }^{3 *}$ \\ ${ }^{1}$ Environmental Engineering, Lancaster University at Beijing Jiaotong University, Weihai, Shandong, 264200, China \\ ${ }^{2}$ Environmental Engineering, Lancaster University at Beijing Jiaotong University, Weihai, Shandong, 264200, China \\ ${ }^{3}$ Environmental Engineering, Lancaster University at Beijing Jiaotong University, Weihai, Shandong, 264200, China
}

\begin{abstract}
Glass antireflection membrane can effectively increase the collection and utilization of sunlight by daylighting equipment, and has been widely used in solar energy related fields. Therefore, exploring the development of high-performance glass antireflection membrane is an essential topic in the current energy utilization research. This paper introduces the general situation of the preparation technology of antireflection membrane internationally, especially the specific method of producing antireflection membrane of silica by sol-gel method in the research. According to the analysis of the results, the significance of membrane surfactant which is similar to Triton X-100 was obtained, and the development prospect of this technology was discussed.
\end{abstract}

\section{Introduction}

With the development of the society, the development and utilization of new energy has become the focus of social attention. Among them, the collection and utilization of solar energy is one of the most significant topics. In order to protect the environment and improve the quality of production and life, the efficient utilization of solar energy is particularly important. Due to the reason of interface reflection, the optical system without coating treatment will weaken the intensity of the transmitted light, the optical system cannot operate efficiently consequently. Antireflection film is a kind of optical film with the widest application range and the largest output. The interference cancellation phenomenon generated when light propagates inside the film is used to effectively reduce the intensity of reflected light on the surface of the element, so that more light passes through the element in the form of transmission. Therefore, in order to solve the problem of interface reflection and improve energy utilization efficiency, it is necessary to coat antireflection film on the surface of the corresponding optical devices to improve the transmission, so as to significantly improve the operating efficiency of the optical system.

Since the 1950s, with the increase of the demand for antireflection film, the technology of high-performance antireflection film preparation has developed rapidly, and the types of antireflection film are becoming more and more abundant. Different types of anti-reflection membranes have different characteristics to meet the needs of different fields:

The $\mathrm{SiO}_{2}$ antireflection film coating prepared by Hot Wire Chemical Vapor Deposition (HWCVD) has the properties of high rate and low residual stress. This antireflection film coating can be used for broadband gap materials and dielectric materials of solar cells ${ }^{[1]}$. The $\mathrm{SiO}_{2}$ antireflection film produced by introducing $\mathrm{SiO}_{2}$ hollow nanospheres $\left(\mathrm{SiO}_{2}\right.$-HNSS) into flexible transparent conductive film (TCF) based on silver nanowires (AGNW) has excellent flexibility, adhesion and thermal stability, which can be widely used in wearable electronic products ${ }^{[2]}$. The $\mathrm{SiO}_{2}$ antireflection film prepared by liquid phase deposition method can change the concentration of $\mathrm{H}_{2} \mathrm{SiF}_{6}$ to control the surface characteristics and grain structure of the film to achieve lower reflectivity. This antireflection film has become a suitable antireflection film for polycrystalline silicon solar cells ${ }^{[3]}$.

In addition to the foregoing, sol-gel method is used in the preparation of new materials such as multifunctional synthetic membranes. Using Sol-gel method to prepare anti-reflection film requires lower reaction temperature, and the reaction is easier to meet the needs of practical application and promotion. Additionally, the component elements can achieve uniform doping on the molecular level. In the meantime, sol-gel method can also effectively adjust the microstructure of thin films. Therefore, with the development of laser technology and applications, sol-gel method has been used as a common method to prepare nanomaterials and thin films with special structures ${ }^{[4]-[7]}$.

The purpose of this research project is to prepare silica antireflection film by sol-gel method under the condition of acid catalysis, and test the performances of transmittance and friction resistance, so as to explore the methods to improve these relevant performances. Therefore, based on the traditional sol-gel method to prepare glass antireflection film, this research project explores the feasibility of improving various properties of antireflection film, in order to promote the progress of the performance of glass antireflection film, and then improve the yield, so as to facilitate the application of glass antireflection film in a wider range.

*Corresponding author's e-mail: xjtian@bjtu.edu.cn 


\section{Materials and Methods}

\subsection{Introduction to sol-gel method}

Sol-gel method is a kind of material preparation method which developed in the 1960s. It was not until 1971 that the German scholar H. Dislich first obtained multicomponent solid materials by sol-gel method that the solgel process attracted extensive attention of the scientific community and was rapidly developed, and accordingly, various optical films, such as antipermeability films and high reverse films, were prepared gradually ${ }^{[8]}$. In this method, metallic inorganic substances or metal alkyl salts are used as raw materials, which are mixed uniformly in liquid phase. Then, a stable transparent sol system is formed in the solution through hydrolysis reactions and condensation reaction. After aging, the colloidal particles polymerize slowly, and the gel with three-dimensional space network structure formed. After drying, sintering and curing, the gel whose networks are filled with solvent that has lost the fluidity, can be prepared into molecular and even nanometer substructure materials.

\subsection{Experimental Reagent and Instrument}

The main raw materials and chemical reagents used in this experiment are shown in Table 1.

Table 1. List of raw materials and chemical reagents.

\begin{tabular}{|c|c|c|c|}
\hline Reagent & Chemical formula & Purity & Manufacturer \\
\hline Tetraethyl orthosilicate & $\mathrm{Si}\left(\mathrm{OC}_{2} \mathrm{H}_{5}\right)_{4}$ & $\mathrm{AR}$ & Sinopharm Shanghai Chemical Reagent Co., Ltd \\
\hline Tetrabutyl titanate & $\mathrm{C}_{16} \mathrm{H}_{36} \mathrm{O}_{4} \mathrm{Ti}$ & AR & Sinopharm Shanghai Chemical Reagent Co., Ltd \\
\hline Anhydrous ethanol & $\mathrm{CH}_{3} \mathrm{CH}_{2} \mathrm{OH}$ & AR & Sinopharm Shanghai Chemical Reagent Co., Ltd \\
\hline Hydrochloric acid & $\mathrm{HCl}$ & AR & Sinopharm Shanghai Chemical Reagent Co., Ltd \\
\hline Deionized water & $\mathrm{H}_{2} \mathrm{O}$ & $\begin{array}{c}\text { Primary } \\
\text { distillation }\end{array}$ & Self-control \\
\hline TritonX-100 & $\mathrm{C}_{14} \mathrm{H}_{22} \mathrm{O}\left(\mathrm{C}_{2} \mathrm{H}_{4} \mathrm{O}\right)_{\mathrm{n}}$ & AR & Sigma Gade chemical plant \\
\hline
\end{tabular}

The main instruments and equipment used in this

experiment are shown in Table 2.

Table 2. List of the equipment and instruments in the experimental process.

\begin{tabular}{|c|c|c|}
\hline Name & Model & Manufacturer \\
\hline Magnetic stirrer & JK-SMS-HS & $\begin{array}{l}\text { Shanghai Jingxue Scientific Instrument Co., } \\
\text { Ltd }\end{array}$ \\
\hline Uniform speed lift coater & Self-made & Huiyin Group \\
\hline Box incinerator & S12 09-10 & $\begin{array}{l}\text { Weihai Golden sun solar thermal power } \\
\text { generation equipment Co., Ltd }\end{array}$ \\
\hline Spectrophotometer & UV-3600 & Shanghai Optical Instrument No.5 factory \\
\hline Metallurgical microscope & $4 \mathrm{XC}$ & Shanghai Optical Instrument No.5 factory \\
\hline Linear abrasion tester & 5750 & Changzhou Sanfeng Technology Co., Ltd \\
\hline $\begin{array}{l}\text { Polyvinylidene fluoride } 0.22 \text { micron filter membrane } \\
\text { (F model) }\end{array}$ & Q/IEF J01-1997 & $\begin{array}{l}\text { Shanghai Xingya purification material } \\
\text { factory }\end{array}$ \\
\hline Biochemical incubator & SPX-100B-Z & $\begin{array}{l}\text { Shanghai Boxun Industry \& Commerce } \\
\text { Co.,Ltd. Medical Equipment Factory }\end{array}$ \\
\hline Taber rubber friction head & MIL-E-12397 & Shenzhen Guangxinda Trade Co., Ltd \\
\hline
\end{tabular}

\subsection{Preparation of sol-gel}

\subsubsection{Preparation of $\mathrm{SiO}_{2}$ sol-gel (method 1)}

Mix $\mathrm{Si}\left(\mathrm{OC}_{2} \mathrm{H}_{5}\right)_{4}$ and $\mathrm{C}_{2} \mathrm{H}_{5} \mathrm{OH}$ reagent proportionally and stir for 30 minutes. Also mix $\mathrm{H}_{2} \mathrm{O}, \mathrm{C}_{2} \mathrm{H}_{5} \mathrm{OH}$ and $\mathrm{HCl}$ reagent proportionally and stir for 20 minutes. The volume ratio of the final monolithic sol preparation reagent is $\mathrm{C}_{2} \mathrm{H}_{5} \mathrm{OH}: \mathrm{H}_{2} \mathrm{O}: \mathrm{HCl}: \mathrm{Si}\left(\mathrm{OC}_{2} \mathrm{H}_{5}\right)_{4}=53.4: 8: 0.088: 20$. Mix the above solution and stir for 2 hours. The speed of magnetic agitator is controlled at $800 \sim 1000 \mathrm{r} / \mathrm{min}$, so that the reaction can be fully contacted between reagents. After obtaining the colorless and transparent $\mathrm{SiO}_{2}$ sol, it was aged in a biochemical incubator for seven days and the aging temperature was controlled at $30^{\circ} \mathrm{C}$. Finally, $\mathrm{SiO}_{2}$ plating solution was obtained for testing.

\subsubsection{Preparation of $\mathrm{SiO}_{2}$ sol-gel (method 2)}

Mix $\mathrm{Si}\left(\mathrm{OC}_{2} \mathrm{H}_{5}\right)_{4}, \mathrm{C}_{2} \mathrm{H}_{5} \mathrm{OH}, \mathrm{H}_{2} \mathrm{O}$ and $\mathrm{HCl}$ reagent proportionally and stir for 2 hours, and the volume ratio of the final monolithic sol preparation reagent is $\mathrm{C}_{2} \mathrm{H}_{5} \mathrm{OH}$ : 
$\mathrm{H}_{2} \mathrm{O}: \mathrm{HCl}: \mathrm{Si}\left(\mathrm{OC}_{2} \mathrm{H}_{5}\right)_{4}=200.14: 6.68: 0.012: 20.65$. The speed of magnetic agitator is controlled at $800 \sim 1000$ $\mathrm{r} / \mathrm{min}$, so that the reaction can be fully contacted between reagents. After obtaining the colorless and transparent $\mathrm{SiO}_{2}$ sol, it was aged in a biochemical incubator for seven days and the aging temperature was controlled at $30^{\circ} \mathrm{C}$. Finally, $\mathrm{SiO}_{2}$ plating solution was obtained for testing.

\subsubsection{Preparation of SiO2 sol-gel with different Triton $X-100$ content}

Mix $\mathrm{Si}\left(\mathrm{OC}_{2} \mathrm{H}_{5}\right)_{4}, \mathrm{C}_{2} \mathrm{H}_{5} \mathrm{OH}, \mathrm{H}_{2} \mathrm{O}, \mathrm{HCl}$ and Triton $\mathrm{X}-100$ reagent proportionally and stir for 2 hours, and the volume ratio of the final monolithic sol preparation reagent is $\mathrm{C}_{2} \mathrm{H}_{5} \mathrm{OH}: \mathrm{H}_{2} \mathrm{O}: \mathrm{HCl}: \mathrm{Si}\left(\mathrm{OC}_{2} \mathrm{H}_{5}\right)_{4}=237.77: 7.936$ : $0.0143: 31.482$. The speed of magnetic agitator is controlled at $800 \sim 1000 \mathrm{r} / \mathrm{min}$, so that the reaction can be fully contacted between reagents. After obtaining the colorless and transparent $\mathrm{SiO}_{2} \mathrm{sol}$, it was aged in a biochemical incubator for seven days and the aging temperature was controlled at $30^{\circ} \mathrm{C}$. The final $\mathrm{SiO}_{2}$ plating solution containing the Triton $\mathrm{X}-100$ is obtained for testing.

\subsection{Practical Operation Procedure of Coating}

\subsection{1 $\mathrm{SiO}_{2}$ sol-gel coating prepared by two methods}

Wash the glass sheet with detergent and deionized water for 15 minutes, then dry with blower.

Method 1: The $\mathrm{SiO}_{2}$ sol-gel coatings were subjected to four different tensile speeds of $2 \mathrm{~mm} / \mathrm{s}, 2.2 \mathrm{~mm} / \mathrm{s}, 2.4 \mathrm{~mm} / \mathrm{s}$ and $2.5 \mathrm{~mm} / \mathrm{s}$, respectively. Put the coated glasses into the muffle furnace at $400^{\circ} \mathrm{C}$ to be solidified for 1 hour. The transmittance was measured after a short cooling time.

Method 2: The $\mathrm{SiO}_{2}$ sol-gel coatings were subjected to four different tensile speeds of $7 \mathrm{~mm} / \mathrm{s}, 7.2 \mathrm{~mm} / \mathrm{s}$, $7.33 \mathrm{~mm} / \mathrm{s}$ and $7.5 \mathrm{~mm} / \mathrm{s}$, respectively. Put the coated glasses into the muffle furnace at $400^{\circ} \mathrm{C}$ to be solidified for 1 hour. The transmittance was measured after a short cooling time.

\subsection{2 $\mathrm{SiO}_{2}$ sol-gel coatings with Triton $\mathrm{X}-100$}

By the preparation and transmittance measurement of silica gel in the first two methods, it is found that the average transmittance of silica gel prepared by method 2 is high, and the optimum tensile speed is $7 \mathrm{~mm} / \mathrm{s}$. Therefore, the second method of preparing silica sol and its solvent ratio are used to prepare it. The prepared sols were divided into 6 groups and the Triton X-100 was added from 1 to $6 \mathrm{~mL}$, respectively.

Clean the glass sheet in the same way. 6 groups of sols with $7 \mathrm{~mm} / \mathrm{s}$ pull-up speed. Put the coated glasses into the muffle furnace at $400^{\circ} \mathrm{C}$ to be solidified for 1 hour. The transmittance was measured after a short cooling time. Finally, suitable samples are selected for friction analysis.

\section{Results \& Discussion}

\subsection{Experimental results of acid-catalyzed silica sol-gel and discussion}

Table 3 shows the average transmittance of each $\mathrm{SiO}_{2}$ solgel film layers catalyzed by acid.

Table 3. Average transmittance of $\mathrm{SiO}_{2}$ sol-gel layers catalyzed by acid.

\begin{tabular}{|c|c|c|c|c|c|c|c|c|}
\hline Sample & $1-\mathrm{SiO}_{2}-1$ & $1-\mathrm{SiO}_{2}-2$ & $1-\mathrm{SiO}_{2}-3$ & $1-\mathrm{SiO}_{2}-4$ & 2_- $\mathrm{SiO}_{2}{ }_{-}$ & 2_- $\mathrm{SiO}_{2}{ }_{2}$ & 2_- $\mathrm{SiO}_{2}{ }_{3}$ & 2_SiO ${ }_{2} 4$ \\
\hline $\begin{array}{c}\text { Average } \\
\text { transmittance (\%) }\end{array}$ & 94 & 93.9 & 93.7 & 93.7 & 94.5 & 93.8 & 94.3 & 94 \\
\hline
\end{tabular}

As can be seen from Table 3, when the traction speed is $7 \mathrm{~mm} / \mathrm{s}$, the average transmittance is the highest. And from figure 1 the transmittance is the highest when the wavelength is about $1800 \mathrm{~nm}$. The solar transmittance is good in the visible range of $400-760 \mathrm{~nm}$, and the transmittance between $400-440 \mathrm{~nm}$ is high.

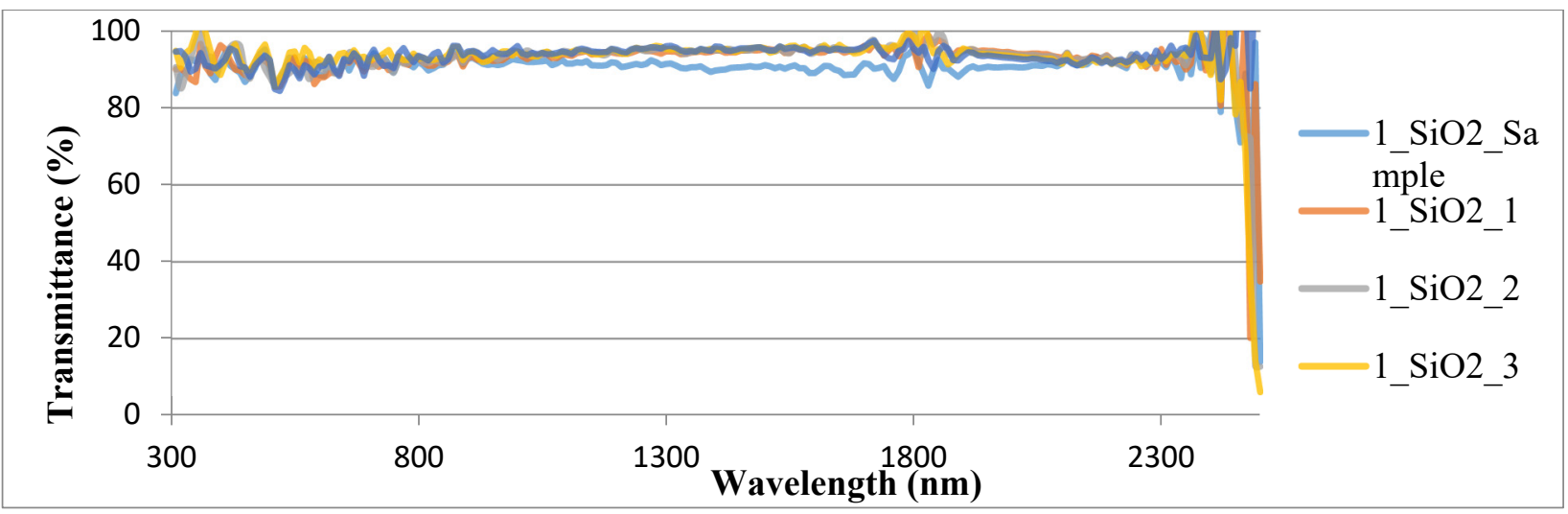

Figure 1. Transmittance of method 1. 


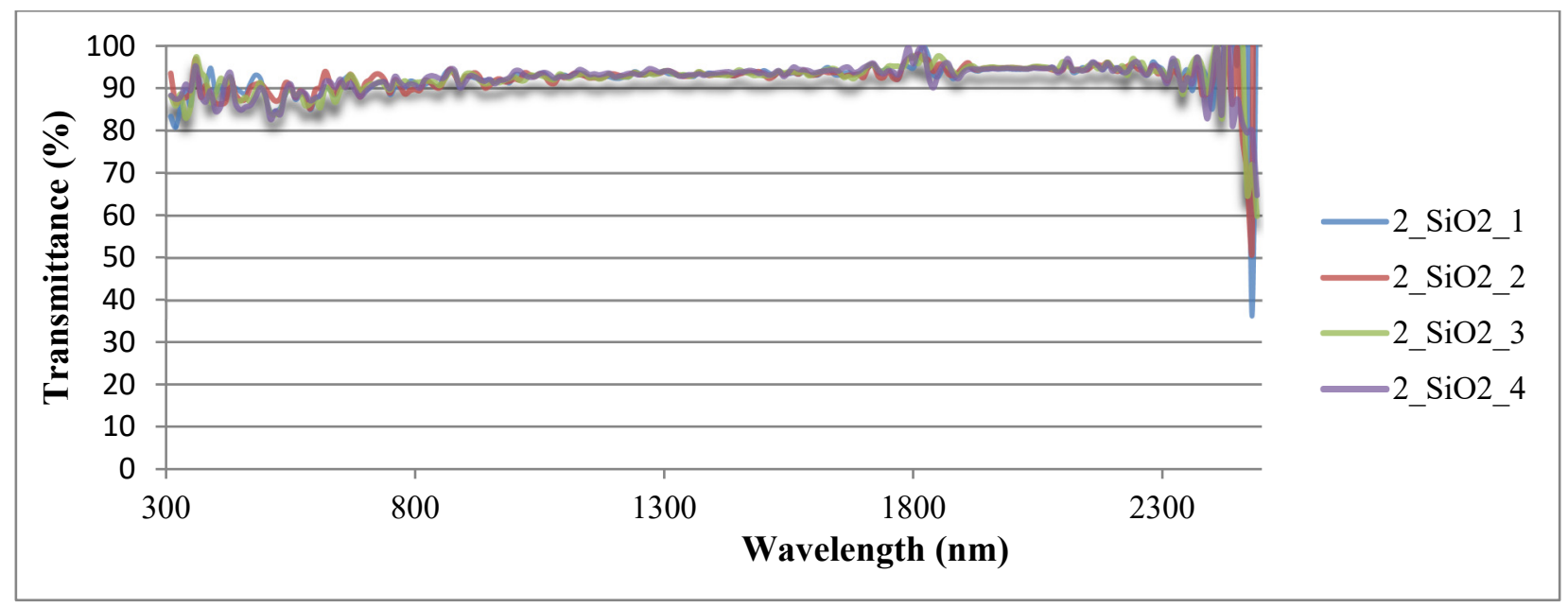

Figure 2. Transmittance of method 2.

\subsection{Experimental results of silica sol-gel membrane layer with Triton X-100 and discussion}

Table 4. Average transmittance of the $\mathrm{SiO}_{2}$ sol-gel films containing the Triton $\mathrm{X}-100$.

\begin{tabular}{|c|c|c|c|c|c|c|c|c|}
\hline Sample & 2_SiO2 $\_1$ & 3_SiO2_1 & 3_SiO2_2 & 3_SiO2_3 & 3_SiO2_4 & 3_SiO2_5 & 3_SiO2_6 & 3_SiO2_2 5 \\
\hline Average transmittance (\%) & 94.5 & 95.2 & 95.5 & 95.5 & 95.3 & 95.9 & 94.5 & 93.2 \\
\hline
\end{tabular}

It can be seen that Triton X-100 improves the overall transmittance of the antireflection film.

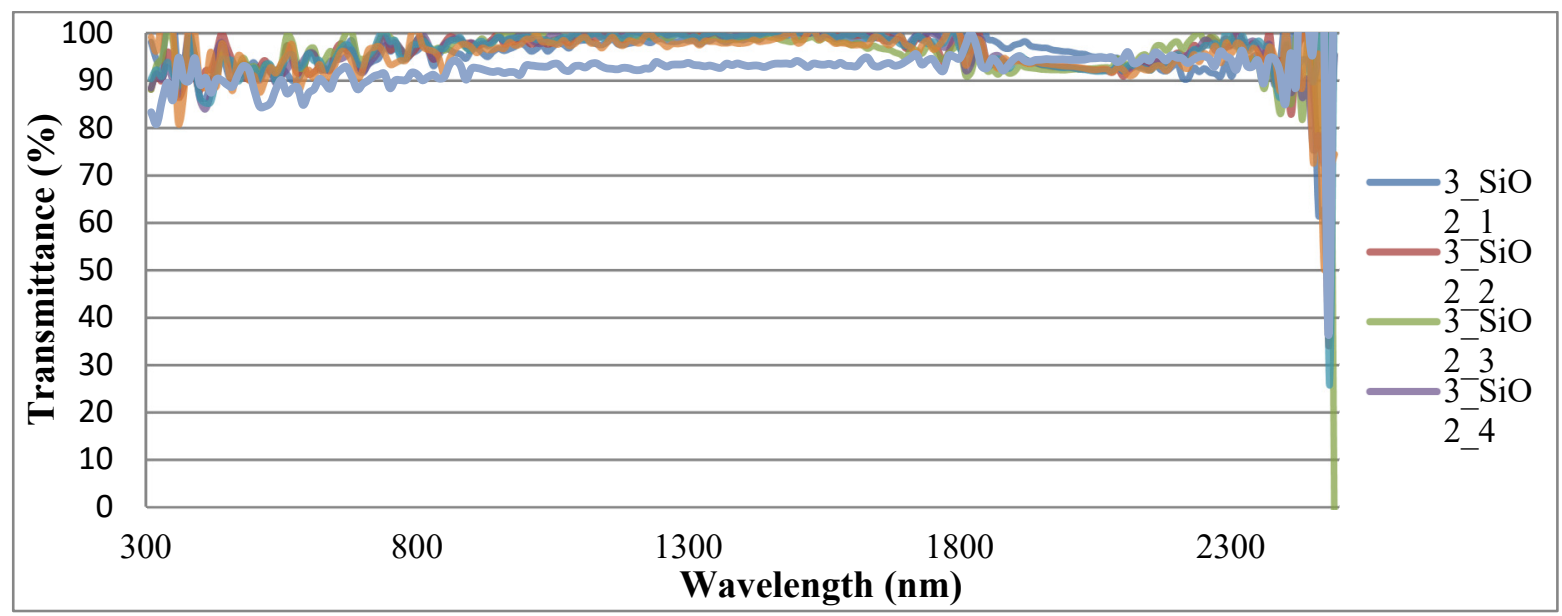

Figure 3. Transmittance of sol with Triton X-100.

By comparison, the average transmittance increased significantly after the addition of Triton X-100. When the amount of Triton X-100 is $5 \mathrm{ml}$, the average transmittance is close to $96 \%$. When the transmittance of each sample was measured, the sample 2 was rubbed with MIL-E12397 plate friction head for 5 times, and the sample 3 SiO2_2_5 was obtained in Table 4. All samples have good transmittance in the infrared region. In addition, its transmittance in visible light range is also increased compared with the original transmittance.

The transmittance of silica gel film before and after friction is compared, as shown in figure. 4. 


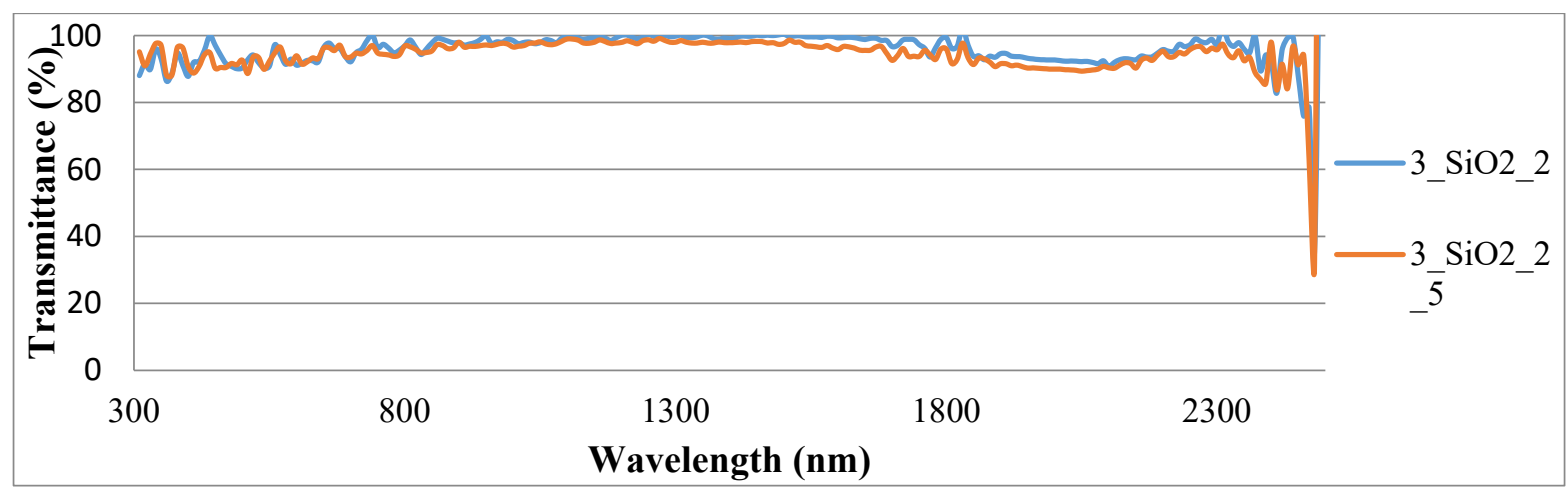

Figure 4. Transmittance before and after friction.

Then, the changes of the film surface before and after friction are observed, as shown in graph 1, respectively.

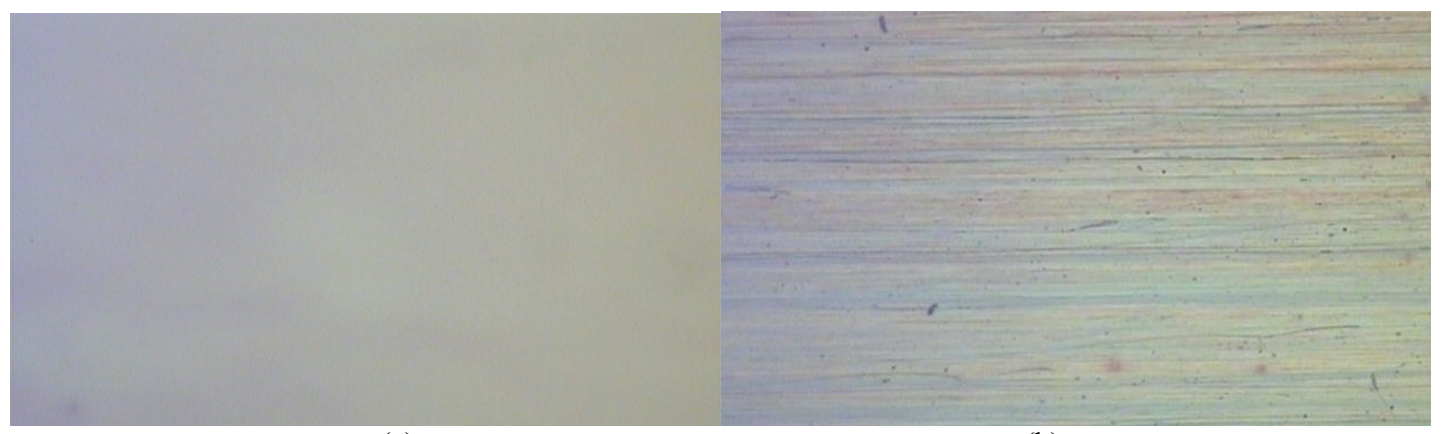

(a)

(b)

Figure 5. (a) Surface of film before friction; (b) Surface of film after friction

After five times of friction, some tiny cracks caused by friction caused a slight decrease in the transmittance of the coating.

\section{Conclusions}

(1) For silica sol-gel prepared under acid-catalyzed conditions, when the traction speed is $7 \mathrm{~mm} / \mathrm{s}$, the average transmittance of the prepared antireflection film is the highest for visible light between 400 and $440 \mathrm{~nm}$.

(2) Regarding silica sol-gel, due to the addition of Triton X-100, the overall transmittance is higher than that of the enhanced film without Triton X-100(when the addition of Triton $\mathrm{X}-100$ is $5 \mathrm{~mL}$, the average transmittance reaches $96 \%$ ), and it is obviously improved in the visible wavelength range.

Therefore, in the process of preparing $\mathrm{SiO}_{2}$ antireflection membrane by sol-gel method under acid catalytic conditions in the future, researchers can consider adding membrane surfactants similar to Triton X-100 to explore the best ratio of related reagents in order to prepare a more perfect multifunctional antireflection membrane.

\section{Acknowledgments}

On the occasion of the completion of this thesis, authors would like to extend the most sincerest thanks to the tutor, Xiujun Tian, Associate Professor of Beijing Jiaotong University.

\section{References}

1. Sittinger, V, Höfer, M, Harig, T, Justianto, M, Thiem, H, Vergöhl, M, \& Schäfer, L. (2018). Optical grade $\mathrm{SiO} 2$ films prepared by HWCVD. Surface \& Coatings Technology, 336, 61-66.

2. Zhang, Liwen, Zhang, Longjiang, Qiu, Yejun, Ji, Yang, Liu, Ya, Liu, Hong, Guo, Qiuquan. (2016). Improved Performance by $\mathrm{SiO} 2$ Hollow Nanospheres for Silver Nanowire-Based Flexible Transparent Conductive Films. ACS Applied Materials \& Interfaces, 8(40), 27055-27063.

3. He, Jing, \& Ke, Yangchuan. (2017). Microstructure developments and anti-reflection properties of $\mathrm{SiO} 2$ films by liquid-phase deposition. Materials Science in Semiconductor Processing, 63, 153-160.

4. Burunkaya, E.; Kesmez, Ö.; Kiraz, N. et al. (2010) $\mathrm{Sn} 4+$ or $\mathrm{Ce} 3+$ doped $\mathrm{TiO} 2$ photocatalytic nanometric films on antireflective nano-SiO2 coated glass. Mater. Chem. Phys., 120(2-3): 272-276.

5. Helsch, G.; Deubener, J. (2012) Compatibility of antireflective coatings on glass for solar applications with photocatalytic properties. Sol. Energy, 86(3): 831-836.

6. Prado, R.; Beobide, G.; Marcaide, A. et al. (2010) Development of multifunctional sol-gel coatings: Anti-reflection coatings with enhanced self-cleaning capacity. Sol. Energy Mater. Sol. Cells, 94(6): 10811088. 
7. Liu, Z.; Zhang, X.; Murakami, T. et al. (2008) Sol-gel $\mathrm{SiO} 2 / \mathrm{TiO} 2$ bilayer films with self-cleaning and antireflection properties. Sol. Energy Mater. Sol. Cells, 92(11):1434-1438.

8. Y Sun. et al. (1996). [J]. Thin Solid Flims, 278: 135139. 